\title{
Endogenous angiotensin II modulates nNOS expression in renovascular hypertension
}

\author{
T.M.C. Pereira ${ }^{1}$, C.M. Balarini ${ }^{1}$, I.V. Silva² ${ }^{2}$ A.M. Cabral ${ }^{1}$, E.C. Vasquez ${ }^{1,3}$ and \\ S.S. Meyrelles ${ }^{1}$ \\ ${ }^{1}$ Laboratório de Transgenes e Controle Cardiovascular, ${ }^{2}$ Laboratório de Biologia Celular e \\ Envelhecimento, Centro de Ciências da Saúde, Universidade Federal do Espírito Santo, Vitória, ES, \\ Brasil \\ ${ }^{3}$ Departamento de Ciências Fisiológicas, Núcleo de Ciências Básicas, Escola Superior de Ciências da \\ Santa Casa de Misericórdia de Vitória (EMESCAM), Vitória, ES, Brasil
}

Correspondence to: S.S. Meyrelles, Laboratório de Transgenes e Controle Cardiovascular, Programa de Pós-Graduação em Ciências Fisiológicas, Centro de Ciências da Saúde, UFES, Av. Marechal Campos, 1468, 29043-900 Vitória, ES, Brasil

Fax+55-27-3335-7330. E-mail: meyrelle.vix@terra.com.br

\begin{abstract}
Nitric oxide (NO) influences renal blood flow mainly as a result of neuronal nitric oxide synthase (nNOS). Nevertheless, it is unclear how nNOS expression is modulated by endogenous angiotensin II, an inhibitor of NO function. We tested the hypothesis that the angiotensin II $A T_{1}$ receptor and oxidative stress mediated by NADPH oxidase contribute to the modulation of renal $\mathrm{nNOS}$ expression in two-kidney, one-clip (2K1C) hypertensive rats. Experiments were performed on male Wistar rats (150 to $170 \mathrm{~g}$ body weight) divided into $2 \mathrm{~K} 1 \mathrm{C}(\mathrm{N}=19)$ and sham-operated $(\mathrm{N}=19)$ groups. nNOS expression in kidneys of $2 \mathrm{~K} 1 \mathrm{C}$ hypertensive rats $(\mathrm{N}=9$ ) was compared by Western blotting to that of $2 \mathrm{~K} 1 \mathrm{C}$ rats treated with low doses of the AT1 antagonist losartan (10 $\left.\mathrm{mg} \cdot \mathrm{kg}^{-1} \cdot \mathrm{day}^{-1} ; \mathrm{N}=5\right)$ or the superoxide scavenger tempol $\left(0.2 \mathrm{mmol} \cdot \mathrm{kg}^{-1} \cdot \mathrm{day}^{-1} ; \mathrm{N}=5\right)$, which still remain hypertensive. After 28 days, nNOS expression was significantly increased by 1.7-fold in the clipped kidneys of $2 \mathrm{~K} 1 \mathrm{C}$ rats and by 3 -fold in the nonclipped kidneys of $2 \mathrm{~K} 1 \mathrm{C}$ rats compared with sham rats, but was normalized by losartan. With tempol treatment, nNOS expression increased 2-fold in the clipped kidneys and 1.4-fold in the non-clipped kidneys compared with sham rats. The changes in nNOS expression were not followed by changes in the enzyme activity, as measured indirectly by the cGMP method. In conclusion, $\mathrm{AT}_{1}$ receptors and oxidative stress seem to be primary stimuli for increased nNOS expression, but this upregulation does not result in higher enzyme activity.
\end{abstract}

Key words: Nitric oxide; Losartan; Tempol; Renovascular hypertension

Research supported by CNPq, State Agency for the Development of Science and Technology (FAPES), and Funds for Science and Technology of the city of Vitória (FACITEC).

Received August 22, 2008. Accepted May 6, 2009

\section{Introduction}

The renin-angiotensin system plays a pivotal role in the development and maintenance of two-kidney, one clip (2K1C) Goldblatt hypertension $(1,2)$. The deleterious vasoconstrictor actions of high tissue levels of angiotensin II (Ang II) can be partially attenuated by some vasodilator mechanisms such as nitric oxide (NO) (3). NO is one of the best vasorelaxant autocoids which, in addition to exerting systemic control of blood pressure (4), also exerts a paracrine control of the microvascular tone in the kidney (5). For example, both acute and chronic inhibition of NO results in a significant increase in renal vascular resistance, confirming its role in the modulation of renal blood flow (6-8).

$\mathrm{NO}$ is produced by three NO synthase isoforms: the so- 
called inducible (iNOS), endothelial (eNOS) and neuronal (nNOS) isoforms. Among them, nNOS seems to play an important protective role in the renal vasculature (9). Selective chronic inhibition of this isoform leads to arterial hypertension and to a transient sensitization of tubuloglomerular feedback, indicating a modulatory role of NO derived from macula densa cells on arteriolar tone and tubuloglomerular feedback (10). nNOS also seems to be important in counteracting Ang II-induced decreases in glomerular filtration rate via the modulation of tubuloglomerular feedback-mediated afferent arteriolar constriction and an important influence on efferent arteriolar tone $(11,12)$.

Although some studies have demonstrated that renal nNOS expression is altered in experimental models of hypertension (13-16) and in rats chronically infused with Ang II $(3,17,18)$, the mechanism by which this endogenous vasoactive peptide modulates nNOS expression is unclear. In the present study, we tested the hypothesis that Ang II $\mathrm{AT}_{1}$ receptor and/or oxidative stress contribute to the modulation of renal nNOS expression in rats with Ang IIdependent hypertension.

\section{Material and Methods}

\section{Animals}

Male Wistar rats weighing 150 to $170 \mathrm{~g}$ were obtained from the breeding facility of the Federal University of Espírito Santo, Brazil. The animals received a normal chow diet and water ad libitum and were housed individually in temperature-controlled rooms $\left(22^{\circ} \mathrm{C}\right)$ under a $12-\mathrm{h}$ light/dark cycle. All experimental procedures were performed in accordance with the National Institutes of Health (NIH) Guide for the Care and Use of Laboratory Animals, and the protocols were previously approved by the Institutional Ethics Committee for Use of Animals (Escola Superior de Ciências da Santa Casa de Misericórdia de Vitória - CEUA/EMESCAM).

\section{Renovascular hypertension}

$2 \mathrm{~K} 1 \mathrm{C}$ renovascular hypertension was induced by applying a silver clip with an internal diameter of $0.2 \mathrm{~mm}$ to the left renal artery under chloral hydrate anesthesia $(100 \mathrm{mg} /$ $\mathrm{kg}$, ip). The $2 \mathrm{~K} 1 \mathrm{C}$ animals ( $\mathrm{N}=19)$ were randomly subdivided into 3 groups: a) untreated animals ( $2 K 1 C, N=9)$, b) animals treated with a subpressor dose of losartan (10 $\mathrm{mg} \cdot \mathrm{kg}^{-1} \cdot$ day $^{-1}$, in drinking water), an Ang II subtype $A T_{1}$ receptor antagonist ( $2 \mathrm{~K} 1 \mathrm{C}$-losartan, $\mathrm{N}=5$ ), and c) animals treated with a subpressor dose of tempol $\left(0.2 \mathrm{mmol} \cdot \mathrm{kg}^{-1}\right.$. day $^{-1}$, in drinking water), a mimetic of superoxide dismutase (2K1C-tempol, $\mathrm{N}=5$ ). Control sham-operated rats ( $\mathrm{N}$ $=5$ ) underwent the same surgical procedure but without clipping the renal artery. Both the $2 \mathrm{~K} 1 \mathrm{C}$ and sham groups were studied 28 days later.

\section{Blood pressure measurements}

Four weeks after renal artery clipping or sham operation, rats were anesthetized with a combination of ketamine and xylazine $(91.0 / 9.1 \mathrm{mg} / \mathrm{kg}$, ip) and a catheter was inserted aseptically into the femoral artery for the direct measurement of mean arterial pressure (MAP) and heart rate $(\mathrm{HR})$. The animals then received a single injection of the antibiotic enrofloxacin $(12 \mathrm{mg} / \mathrm{kg}, \mathrm{im})$. One day after catheter placement, MAP and HR were measured in conscious, freely moving rats, in their own cages using a disposable blood pressure transducer (Cobe Laboratories, USA) connected to a pressure processor amplifier and data-acquisition system (MP100, Biopac Systems, USA). Data were analyzed on a beat-to-beat basis to quantify baseline values of MAP and HR.

\section{Western blot analysis}

Immediately after euthanasia, blood was removed by PBS perfusion. The kidney cortex and medulla were separated and homogenized with a protease inhibitor cocktail (Product \#P2714, Sigma Aldrich, USA) dissolved in distilled water at $0.1 \mu \mathrm{L} / \mathrm{mg}$ protein, and centrifuged at 10,000 $g$ for $15 \mathrm{~min}$. Protein concentration was quantified by the method of Bradford (19). The protein samples (100 $\mu \mathrm{g})$ were submitted to SDS-PAGE (5\%), under non-reducing conditions, electroblotting and the test of equal loading of protein using red Ponceau (GE Healthcare, Germany). If the homogeneity of protein loading was not confirmed, the experiment was discarded. When confirmed, nitrocellulose membranes (GE Healthcare) were blocked with 10\% skimmed milk in $0.1 \%$ PBS-Tween 20 for 60 min at room temperature. The membranes were then incubated with a polyclonal antibody for the nNOS (type I) isoform (Santa Cruz Biotechnology, USA) at 1:250 dilution at $4^{\circ} \mathrm{C}$, followed by incubation with horseradish peroxidase-labeled secondary anti-rabbit antibody (GE Healthcare) at 1:3000 dilution. Bands were detected by enhanced chemiluminescence (GE Healthcare), and band intensity was measured by densitometry using a Scion Image System (public domain, NIH, USA). Each electrophoretic run was performed with duplicate samples of both clipped and nonclipped kidneys from $2 \mathrm{~K} 1 \mathrm{C}$ and sham animals in the same polyacrylamide gel. This procedure was repeated for the $2 \mathrm{~K} 1 \mathrm{C}$ animals treated with losartan or tempol. Rat pituitary lysate was used as nNOS-positive control.

\section{Quantitation of cyclic GMP levels}

The kidneys of several animals were quickly immersed 
in $10 \mathrm{mM}$ PBS containing 3 isobutyl-1-methylxanthine $(0.1$ $\mathrm{mM}$ diluted in DMSO at 1:1000), a nonspecific phosphodiesterase inhibitor. The kidneys were then homogenized, centrifuged $(10,000 \mathrm{~g}$ for $15 \mathrm{~min})$, immediately frozen in liquid nitrogen, and stored at $-20^{\circ} \mathrm{C}$. nNOS bioavailability was indirectly quantified by an enzyme immunoassay of cyclic GMP (cGMP) using a specific kit (Product \#RPN226, GE Healthcare). This was performed in the presence of acetylated samples to increase the sensitivity of the assay, as previously reported (20). Data are reported as $\mathrm{fmol} / \mathrm{mg}$ protein, with protein being measured by the method of Bradford (19).

\section{Statistical analysis}

Data are reported as means \pm SEM. Statistical analysis was performed by two-way ANOVA followed by the Fisher post hoc test for multiple comparisons. The level of significance was set at $P<0.05$.

\section{Results}

Figure 1 summarizes the resting MAP values obtained in conscious animals 28 days after renal artery clipping. As expected, MAP was significantly higher in $2 \mathrm{~K} 1 \mathrm{C}$ rats (179 $\pm 5 \mathrm{mmHg})$ than in sham rats $(101 \pm 3 \mathrm{mmHg}, \mathrm{P}<0.01)$. Administration of a subpressor dose of losartan, an $\mathrm{AT}_{1}$ receptor antagonist $\left(10 \mathrm{mg} \cdot \mathrm{kg}^{-1} \cdot \mathrm{day}^{-1}\right)$, for 4 weeks decreased but did not normalize MAP $(140 \pm 7 \mathrm{mmHg})$ compared with sham and $2 \mathrm{~K} 1 \mathrm{C}$ rats. MAP $(165 \pm 6 \mathrm{mmHg})$ was not decreased in $2 \mathrm{~K} 1 \mathrm{C}$ animals treated with a low dose of tempol, a superoxide dismutase mimetic $(0.2$ $\mathrm{mmol} \cdot \mathrm{kg}^{-1} \cdot \mathrm{day}^{-1}$ ), for 4 weeks.

Table 1 shows the kidney weight/body weight ratio of $2 \mathrm{~K} 1 \mathrm{C}$ rats compared with sham rats. As expected, 4 weeks after renal artery clipping, hypertensive animals showed a significant decrease in the weight of the clipped kidney (atrophy) and a significant increase in the weight of the non-clipped kidney (hypertrophy) compared with sham rats. The administration of losartan or tempol for 4 weeks to $2 \mathrm{~K} 1 \mathrm{C}$ rats did not prevent the atrophy of the clipped kidney, but exacerbated the hypertrophy of the non-clipped kidney.

Figures 2, 3, and 4 show representative Western blot bands and average values for nNOS protein expression in the renal cortex of untreated and treated $2 \mathrm{~K} 1 \mathrm{C}$ rats compared with sham rats. As shown in Figure 2, the $2 \mathrm{~K} 1 \mathrm{C}$ hypertensive rats showed increased nNOS protein expression in the cortex of both clipped and, more extensively, non-clipped kidneys (absorbance: $0.27 \pm 0.03$ and $0.43 \pm 0.03$, respectively) compared with the sham group (absorbance: $0.16 \pm 0.03$ and $0.14 \pm 0.02$, respectively; $P$
$<0.05)$. The treatment of $2 \mathrm{~K} 1 \mathrm{C}$ rats with a subpressor dose of losartan prevented the increase of nNOS expression in the cortex of both clipped and non-clipped kidneys (absorbance: $0.25 \pm 0.03$ and $0.22 \pm 0.01$, respectively) compared with sham rats (absorbance: $0.29 \pm 0.02$ and $0.27 \pm 0.01$, respectively; Figure 3 ). On the other hand, treatment of $2 \mathrm{~K} 1 \mathrm{C}$ rats with a subpressor dose of tempol, a superoxide dismutase mimetic, prevented the increase of nNOS expression in the cortex of the clipped, but not of the non-clipped kidneys (absorbance: $0.35 \pm 0.08$ and $0.27 \pm$ 0.06 , respectively) compared with sham rats (absorbance: $0.17 \pm 0.03$ and $0.19 \pm 0.06$, respectively; $P<0.05$; Figure 4).

Figure 5 shows the average values of cGMP in the kidney cortex of the hypertensive $2 \mathrm{~K} 1 \mathrm{C}$ and sham groups.

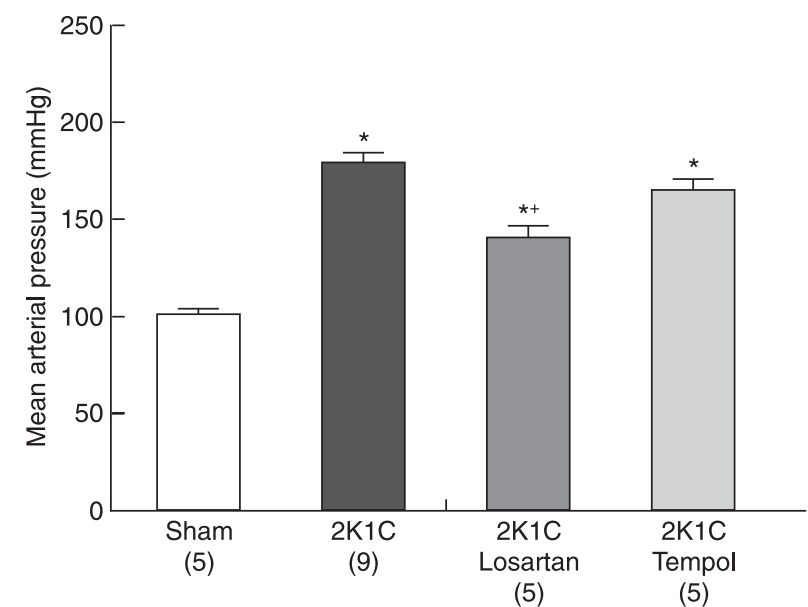

Figure 1. Average resting mean arterial pressure in 2-kidney, 1clip $(2 \mathrm{~K} 1 \mathrm{C})$ rats and $2 \mathrm{~K} 1 \mathrm{C}$ rats treated with low doses of losartan (10 $\left.\mathrm{mg} \cdot \mathrm{kg}^{-1} \cdot \mathrm{day}^{-1}\right)$ or tempol $\left(0.2 \mathrm{mmol} \cdot \mathrm{kg}^{-1} \cdot \mathrm{day}^{-1}\right)$, compared with sham rats. Data are reported as means \pm SEM for the number of rats in parentheses. ${ }^{*} \mathrm{P}<0.01$ vs sham group and ${ }^{+} \mathrm{P}<$ 0.05 vs $2 \mathrm{~K} 1 \mathrm{C}$ group (ANOVA).

Table 1. Kidney weight/body weight ratio in 2-kidney, 1-clip $(2 \mathrm{~K} 1 \mathrm{C})$ rats untreated or treated with low doses of losartan (10 $\mathrm{mg} \cdot \mathrm{kg}^{-1} \cdot$ day $\left.^{-1}\right)$ or tempol $\left(0.2 \mathrm{mmol} \cdot \mathrm{kg}^{-1} \cdot \mathrm{day}^{-1}\right)$ compared with sham-operated rats.

\begin{tabular}{lcc}
\hline Group & \multicolumn{2}{c}{ Kidney weight $(\mathrm{mg}) /$ body weight $(\mathrm{g})$ ratio } \\
\cline { 2 - 3 } & $\begin{array}{c}\text { Left kidney } \\
\text { (clipped) }\end{array}$ & $\begin{array}{c}\text { Right kidney } \\
\text { (non-clipped) }\end{array}$ \\
\hline Sham $(\mathrm{N}=6)$ & $2.89 \pm 0.13$ & $2.94 \pm 0.14$ \\
$2 \mathrm{~K} 1 \mathrm{C}(\mathrm{N}=9)$ & $2.57 \pm 0.14^{\#}$ & $3.85 \pm 0.10^{\text {*\# }}$ \\
$2 \mathrm{~K} 1 \mathrm{C}+$ losartan $(\mathrm{N}=5)$ & $2.34 \pm 0.07^{\#}$ & $4.93 \pm 0.18^{\text {*\#+ }}$ \\
$2 \mathrm{~K} 1 \mathrm{C}+$ tempol $(\mathrm{N}=7)$ & $2.95 \pm 0.03$ & $4.85 \pm 0.34^{\text {*\#+ }}$
\end{tabular}

Data are reported as means \pm SEM. ${ }^{*} P<0.05$ vs clipped kidney; ${ }^{\#} \mathrm{P}<0.05$ vs sham group; ${ }^{+} \mathrm{P}<0.05$ vs $2 \mathrm{~K} 1 \mathrm{C}$ (ANOVA). 

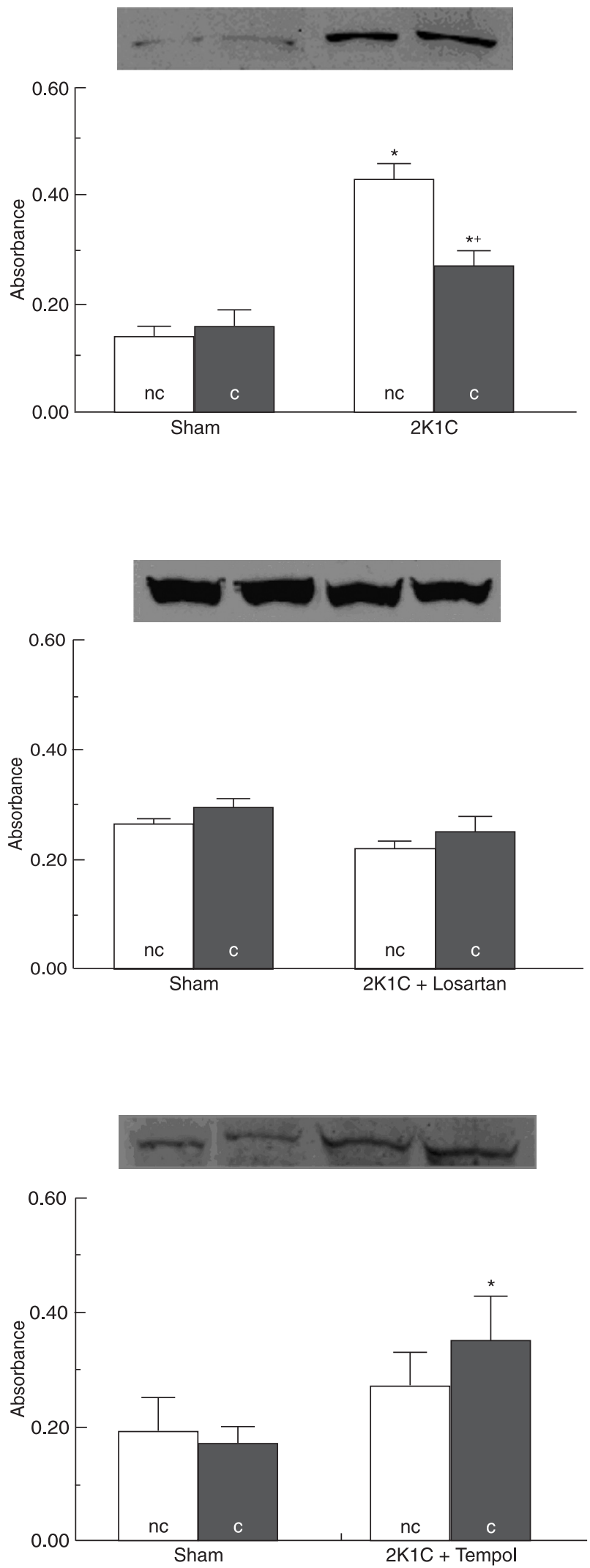

Figure 2. Neuronal nitric oxide synthase (nNOS) protein expression in clipped (c) and non-clipped (nc) kidney cortex of twokidney, 1-clip (2K1C) hypertensive rats compared with sham rats. The upper panel shows a representative Western blot of nNOS expression. Data are reported as means \pm SEM of nNOS expression for 9 rats in each group indicated by absorbance measurements of the Western blot. ${ }^{*} \mathrm{P}<0.05$ vs sham group; ${ }^{+} \mathrm{P}$ $<0.05$ vs non-clipped kidney cortex of $2 \mathrm{~K} 1 \mathrm{C}$ rats (ANOVA)

Figure 3. Neuronal nitric oxide synthase (nNOS) protein expression in clipped (c) and non-clipped (nc) kidney cortex of twokidney, 1-clip (2K1C) hypertensive rats treated with low doses of losartan $\left(10 \mathrm{mg} \cdot \mathrm{kg}^{-1} \cdot \mathrm{day}^{-1}\right)$ compared with sham rats. The upper panel shows a representative Western blot of nNOS expression. Data are reported as means \pm SEM of nNOS expression for 4 rats in each group indicated by absorbance measurements of the Western blot.

Figure 4. Neuronal nitric oxide synthase (nNOS) protein expression in clipped (c) and non-clipped (nc) kidney cortex of twokidney, 1-clip (2K1C) hypertensive rats treated with low doses of tempol $\left(0.2 \mathrm{mmol} \cdot \mathrm{kg}^{-1} \cdot\right.$ day $\left.^{-1}\right)$ compared with sham rats. The upper panel shows a representative Western blot of nNOS expression. Data are reported as means \pm SEM of nNOS expression for 5 rats in each group indicated by absorbance measurements of the Western blot. ${ }^{*} \mathrm{P}<0.05$ vs sham group (ANOVA). 


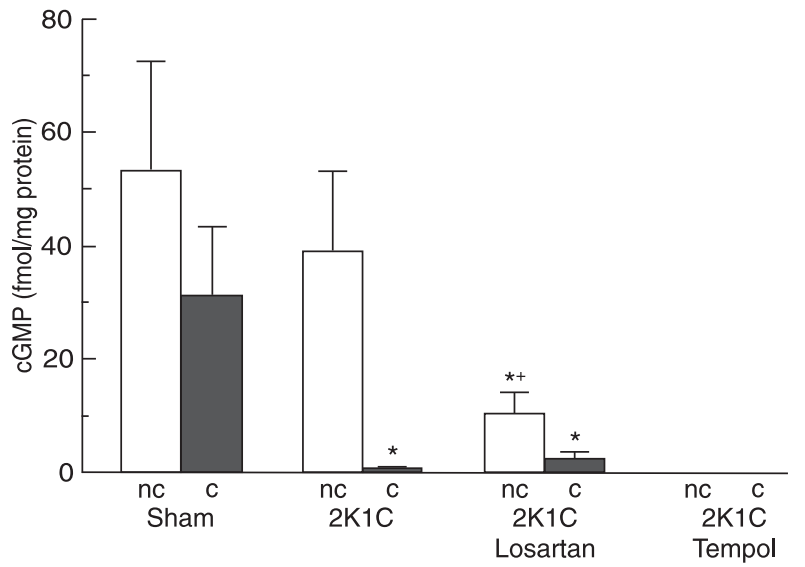

The cortex of the clipped kidney showed significantly reduced levels of cGMP in untreated $2 \mathrm{~K} 1 \mathrm{C}(0.9 \pm 0.06 \mathrm{fmol} /$ $\mathrm{mg}$ protein) and in $2 \mathrm{~K} 1 \mathrm{C}$ animals treated with a low dose of losartan $(2.5 \pm 1.25 \mathrm{fmol} / \mathrm{mg}$ protein) or tempol (undetectable values) compared with the sham group (31.2 \pm 12.2 $\mathrm{fmol} / \mathrm{mg}$ protein; $\mathrm{P}<0.05)$. In the non-clipped kidney cortex, the production of cGMP was similar in $2 \mathrm{~K} 1 \mathrm{C}$ and sham rats (39.2 \pm 14.1 and $53.2 \pm 19.3 \mathrm{fmol} / \mathrm{mg}$ protein), but was significantly decreased in $2 \mathrm{~K} 1 \mathrm{C}$ rats treated with a subpressor dose of losartan (10.7 $\pm 5.7 \mathrm{fmol} / \mathrm{mg}$ protein) or tempol (undetectable) compared with sham rats $(P<0.05)$.

\section{Discussion}

The main objective of this study was to evaluate renal nNOS expression in Goldblatt renovascular hypertension. The novel finding in this study was that the arterial hypertension following long-term unilateral stenosis of the renal artery is characterized by an increased expression of nNOS in the clipped and, more extensively, in the nonclipped kidney. Our data indicate that $A T_{1}$ receptors and oxidative stress could be primary stimuli for the increased nNOS expression, although the enzyme activity seems to be diminished, as indirectly indicated by cGMP quantitation.

Losartan at doses of approximately $10 \mathrm{mg} / \mathrm{kg}$ has been used in other experimental models of arterial hypertension to block $A T_{1}$ receptors without marked changes in high blood pressure $(21,22)$. In the present study, we used a model of Ang II-dependent hypertension and this could explain why losartan at the dose used attenuated the increase in MAP. However, losartan-treated $2 \mathrm{~K} 1 \mathrm{C}$ animals still showed a marked arterial hypertension compared to the sham group $(140 \pm 7$ and $101 \pm 3 \mathrm{mmHg})$. On the other hand, treatment of $2 \mathrm{~K} 1 \mathrm{C}$ rats with tempol, a specific and potent short-acting superoxide radical scavenger anion,
Figure 5. cGMP levels in clipped (c) and non-clipped (nc) kidney cortex of two-kidney, 1-clip (2K1C), 2K1C treated with low doses of losartan or tempol compared with sham rats. $\mathrm{N}=3$ in each group. Data are reported as means \pm SEM. ${ }^{*} P<0.05$ vs sham group and ${ }^{+} \mathrm{P}<0.05$ vs $2 \mathrm{~K} 1 \mathrm{C}$ group (ANOVA).

did not cause significant changes in MAP.

The contribution of Ang II to the hypertrophy of the nonclipped kidney of $2 \mathrm{~K} 1 \mathrm{C}$ animals is not known. In the present study, we observed that the $2 \mathrm{~K} 1 \mathrm{C}$ and mainly the $2 \mathrm{~K} 1 \mathrm{C}$-losartan and $2 \mathrm{~K} 1 \mathrm{C}$-tempol groups showed an increase in the weight of the non-clipped kidney. The greater hypertrophy could be due, at least in part, to the blockade of $\mathrm{AT}_{1}$ receptors in the $2 \mathrm{~K} 1 \mathrm{C}$-losartan group and to the antioxidative stress in both the $2 \mathrm{~K} 1 \mathrm{C}$-losartan and $2 \mathrm{~K} 1 \mathrm{C}$ tempol groups.

Our data showing increased nNOS expression in $2 \mathrm{~K} 1 \mathrm{C}$ hypertensive rats, an experimental model of increased intrarenal levels of Ang II (2), support the view that this enzyme is modulated by the vasoactive peptide Ang II, exerting a compensatory mechanism in both clipped and non-clipped kidneys of $2 \mathrm{~K} 1 \mathrm{C}$ rats. In order to better elucidate the mechanisms involved in enhanced nNOS expression, we also performed the losartan treatment in $2 \mathrm{~K} 1 \mathrm{C}$ rats. The restoration of basal levels of nNOS expression by a low dose of losartan confirmed the hypothesis that nNOS overexpression is mediated by Ang II through $\mathrm{AT}_{1}$ receptors (23) but not by high blood pressure per se or by other angiotensin receptors (24). Our result of nNOS overexpression in the kidney agrees with the finding that Ang II blockade leads to an impairment of NO bioavailability (25). However, the participation of eNOS in $2 \mathrm{~K} 1 \mathrm{C}$ hypertension cannot be excluded, in view of the evidence of an increase of both nNOS and eNOS expression in this model even under conditions of augmented oxidative stress (26). On the other hand, the contribution of the iNOS isoform to our finding can be ruled out based on evidence from the same investigators showing the absence of an inflammatory process in both kidneys of chronic $2 \mathrm{~K} 1 \mathrm{C}$ rats. Interestingly, nNOS overexpression in $2 \mathrm{~K} 1 \mathrm{C}$ animals was lower in the clipped kidney compared with the non-clipped kidney $(\mathrm{P}<$ 0.05). Considering the finding that rats subjected to a 
hypobaric environment showed reduced NOS (27), it may be possible that the hypoxia of the clipped kidneys could contribute to the attenuated up-regulation of nNOS, even though this experimental model is characterized by high levels of intrarenal Ang II (2).

Since NADPH oxidase activity can be stimulated by $A T_{1}$ receptors (28), we also investigated the participation of oxidative stress in nNOS overexpression, and observed that treatment with tempol restored nNOS expression to basal levels in the non-clipped kidney. This finding indicated that, in addition to the role played by intracellular calcium (29), superoxide anions could also participate in the intracellular mechanism of nNOS up-regulation. Interestingly, nNOS expression in the clipped kidney was increased after the antioxidant treatment. A reasonable explanation for this result is based on previous studies $(30,31)$ showing high levels of the anti-proteolytic agent hypoxia inducible factor (HIF-1) under hypoxic conditions. Since oxidative stress has deleterious effects on HIF-1 expression (32), it is possible that, under clip-induced renal artery reduction of blood flow, the antioxidant tempol acted by preserving HIF-1 expression, consequently inhibiting tissue proteolysis and protecting against nNOS degradation. The anti-proteolytic effect of HIF-1 could also explain the smaller atrophy of the clipped kidney of tempol-treated $2 \mathrm{~K} 1 \mathrm{C}$ rats compared to the other $2 \mathrm{~K} 1 \mathrm{C}$ groups.

Cervenka et al. (18) reported that the selective antagonism of nNOS led to a significant reduction of renal hemodynamics in normotensive rats, but not in Ang Il-infused rats, suggesting that nNOS activity is diminished in hypertensive animals. However, in the present study, we meas-

\section{References}

1. Kobori H, Nangaku M, Navar LG, Nishiyama A. The intrarenal renin-angiotensin system: from physiology to the pathobiology of hypertension and kidney disease. Pharmacol Rev 2007; 59: 251-287.

2. Navar LG, Zou L, Von Thun A, Tarng WC, Imig JD, Mitchell $\mathrm{KD}$. Unraveling the mystery of Goldblatt hypertension. News Physiol Sci 1998; 13: 170-176.

3. Navar LG, Ichihara A, Chin SY, Imig JD. Nitric oxide-angiotensin II interactions in angiotensin II-dependent hypertension. Acta Physiol Scand 2000; 168: 139-147.

4. Evans RG, Szenasi G, Anderson WP. Effects of NG-nitro-Larginine on pressure natriuresis in anaesthetized rabbits. Clin Exp Pharmacol Physiol 1995; 22: 94-101.

5. Majid DS, Navar LG. Nitric oxide in the control of renal hemodynamics and excretory function. Am J Hypertens 2001; 14: 74S-82S

6. Erley CM, Heyne N, Friedrich B, Schmidt T, Strobel U, ured renal nNOS expression and observed that it was significantly increased in $2 \mathrm{~K} 1 \mathrm{C}$ hypertensive rats. To reconcile this obvious contradiction, we can assume that the enzyme activity, but not the protein level of nNOS, is decreased, as indirectly quantified by the cGMP method. These data could help explain why the hypertensive Ang II-infused rats did not present improvement of renal function in the study by these investigators (18). In agreement with our results, Murakami et al. (13) showed that nNOS expression was increased in rats infused with Ang II for 14 days and reduced in DOCA-salt hypertensive rats, a model of low Ang II levels.

In agreement with our results, there are indications that systemic oxidative stress is increased in renovascular hypertension $(33,34)$, which could lead to an enhanced release of superoxide anions $\left(\mathrm{O}_{2}^{-}\right)$, mainly due to Ang II $(28,35)$. Moreover, others have shown that nNOS can generate superoxide anions, mainly under situations of depletion of substrates or co-factors (35), also contributing to $\mathrm{O}_{2}^{-}$production and impaired $\mathrm{NO}$ bioavailability. The reason $2 \mathrm{~K} 1 \mathrm{C}$ animals treated with low doses of losartan or tempol showed a marked reduction of cGMP levels may have been that they were still Ang II-dependent hypertensive when compared with sham animals. In addition, the low or undetectable levels of cGMP mainly in the nonclipped kidney of 2K1C-losartan and 2K1C-tempol rats was expected because the levels of the second messenger follow the expression of nNOS, which was restored in these two groups when compared with the $2 \mathrm{~K} 1 \mathrm{C}$ group. Although in the present study we did not measure the expression of eNOS, its participation should be considered.
Wehrmann M, et al. Differential renal response to Nomeganitro-L-arginine methyl ester and L-arginine in rats with hypertensive or diabetic nephropathy. J Cardiovasc Pharmacol 2002; 40: 780-788.

7. Nishiyama A, Fujisawa Y, Fukui T, Rahman M, Kondo N, Ogawa $Y$, et al. Role of nitric oxide in regional blood flow in angiotensin II-induced hypertensive rats. Hypertens Res 2001; 24: 421-427.

8. Sigmon DH, Beierwaltes WH. Influence of nitric oxide derived from neuronal nitric oxide synthase on glomerular filtration. Gen Pharmacol 2000; 34: 95-100.

9. Kone BC, Baylis C. Biosynthesis and homeostatic roles of nitric oxide in the normal kidney. Am J Physiol 1997; 272: F561-F578.

10. Ollerstam A, Pittner J, Persson AE, Thorup C. Increased blood pressure in rats after long-term inhibition of the neuronal isoform of nitric oxide synthase. J Clin Invest 1997; 99: 
2212-2218.

11. Ollerstam A, Salomonsson M, Persson AE. Reduced rat renal vascular response to angiotensin II after chronic inhibition of nNOS. Acta Physiol Scand 2002; 176: 245-252.

12. Tojo A, Onozato ML, Fujita T. Role of macula densa neuronal nitric oxide synthase in renal diseases. Med $\mathrm{Mol}$ Morphol 2006; 39: 2-7.

13. Murakami K, Tsuchiya K, Naruse M, Naruse K, Demura H, Arai $\mathrm{J}$, et al. Nitric oxide synthase I immunoreactivity in the macula densa of the kidney is angiotensin II dependent. Kidney Int Suppl 1997; 63: S208-S210.

14. Cervenka L, Kramer HJ, Maly J, Vaneckova I, Backer A, Bokemeyer $\mathrm{D}$, et al. Role of nNOS in regulation of renal function in hypertensive Ren-2 transgenic rats. Physiol Res 2002; 51: 571-580.

15. Kumar $U$, Shin $Y$, Wersinger $C$, Patel $Y$, Sidhu A. Diminished expression of constitutive nitric oxide synthases in the kidney of spontaneously hypertensive rat. Clin Exp Hypertens 2003; 25: 271-282.

16. Dobrian AD, Schriver SD, Prewitt RL. Role of angiotensin II and free radicals in blood pressure regulation in a rat model of renal hypertension. Hypertension 2001; 38: 361-366.

17. Moreno C, Lopez A, Llinas MT, Rodriguez F, Lopez-Farre $A$, Nava $E$, et al. Changes in NOS activity and protein expression during acute and prolonged ANG II administration. Am J Physiol Regul Integr Comp Physiol 2002; 282: R31-R37.

18. Cervenka L, Kramer HJ, Maly J, Heller J. Role of nNOS in regulation of renal function in angiotensin II-induced hypertension. Hypertension 2001; 38: 280-285.

19. Bradford MM. A rapid and sensitive method for the quantitation of microgram quantities of protein utilizing the principle of protein-dye binding. Anal Biochem 1976; 72: 248-254.

20. Villeneuve N, Fortuno A, Sauvage M, Fournier N, Breugnot $\mathrm{C}$, Jacquemin $\mathrm{C}$, et al. Persistence of the nitric oxide pathway in the aorta of hypercholesterolemic apolipoprotein-Edeficient mice. J Vasc Res 2003; 40: 87-96.

21. Robert V, Heymes C, Silvestre JS, Sabri A, Swynghedauw B, Delcayre C. Angiotensin AT1 receptor subtype as a cardiac target of aldosterone: role in aldosterone-salt-induced fibrosis. Hypertension 1999; 33: 981-986.

22. Bayorh MA, Ganafa AA, Eatman D, Walton M, Feuerstein GZ. Simvastatin and losartan enhance nitric oxide and reduce oxidative stress in salt-induced hypertension. $A m ~ J$ Hypertens 2005; 18: 1496-1502.
23. Pueyo ME, Arnal JF, Rami J, Michel JB. Angiotensin II stimulates the production of $\mathrm{NO}$ and peroxynitrite in endothelial cells. Am J Physiol 1998; 274: C214-C220.

24. Siragy HM, Carey RM. The subtype 2 (AT2) angiotensin receptor mediates renal production of nitric oxide in conscious rats. J Clin Invest 1997; 100: 264-269.

25. Thorup C, Kornfeld M, Goligorsky MS, Moore LC. AT1 receptor inhibition blunts angiotensin II-stimulated nitric oxide release in renal arteries. J Am Soc Nephrol 1999; 10 (Suppl 11): S220-S224.

26. Bosse HM, Bachmann S. Immunohistochemically detected protein nitration indicates sites of renal nitric oxide release in Goldblatt hypertension. Hypertension 1997; 30: 948-952.

27. Barton $\mathrm{CH}, \mathrm{Ni} Z$, Vaziri ND. Blood pressure response to hypoxia: role of nitric oxide synthase. Am J Hypertens 2003; 16: 1043-1048.

28. Toda N, Ayajiki K, Okamura T. Interaction of endothelial nitric oxide and angiotensin in the circulation. Pharmacol Rev 2007; 59: 54-87.

29. Liu R, Persson AE. Angiotensin II stimulates calcium and nitric oxide release from macula densa cells through AT1 receptors. Hypertension 2004; 43: 649-653.

30. Heyman SN, Rosenberger C, Rosen S. Regional alterations in renal haemodynamics and oxygenation: a role in contrast medium-induced nephropathy. Nephrol Dial Transplant 2005; 20 (Suppl 1): i6-i11.

31. Palm F, Connors SG, Mendonca M, Welch WJ, Wilcox CS. Angiotensin II type 2 receptors and nitric oxide sustain oxygenation in the clipped kidney of early Goldblatt hypertensive rats. Hypertension 2008; 51: 345-351.

32. Zhu $X Y$, Chade $A R$, Rodriguez-Porcel M, Bentley MD, Ritman EL, Lerman A, et al. Cortical microvascular remodeling in the stenotic kidney: role of increased oxidative stress. Arterioscler Thromb Vasc Biol 2004; 24: 1854-1859.

33. Lerman LO, Nath KA, Rodriguez-Porcel M, Krier JD, Schwartz RS, Napoli C, et al. Increased oxidative stress in experimental renovascular hypertension. Hypertension 2001; 37: 541-546.

34. Agarwal R, Campbell RC, Warnock DG. Oxidative stress in hypertension and chronic kidney disease: role of angiotensin II. Semin Nephrol 2004; 24: 101-114.

35. Harrison DG, Gongora MC, Guzik TJ, Vidder J. Oxidative stress and hypertension. J Am Soc Hypertens 2007; 1: 3044. 